\title{
The age related amyloids: a growing family of unique biochemical substances
}

\author{
G G Cornwell III, K H Johnson, P Westermark
}

\section{Introduction}

The age related amyloids have come of age. The increasing attention devoted to $\mathrm{Alz}$ heimer's disease in recent years has cast a spotlight on $\beta$ protein, the amyloid fibril protein associated with this disease. However, there is a multitude of other age related amyloids which have been identified. In some instances, the fibril proteins have been identified, whereas, in other cases, the biochemical nature of the amyloids remains unknown (table). Senile systemic amyloid (formerly designated senile cardiac amyloid) is the only clear-cut systemic form of age related amyloid, although the precursor proteins of some localised forms have been identified in the general circulation. In the localised forms the fibril protein precursors are synthesised in the tissue involved by the amyloid.

As a group, the amyloid fibril proteins do not contain a common amino acid sequence essential for the development of the characteristic non-branching fibrils. Of the 17 fibril proteins that have been extracted and sequenced so far, some have been familiar, while others have been novel. One protein, transthyretin (TTR) (prealbumin), has been associated with entirely different forms of amyloidosis in the wild-type and mutated forms. The primary structures of these proteins are critical to the formation of amyloid, its sites of deposition and the clinical manifestations, if any. These proteins must accommodate the development of a $\beta$-pleated sheet (antiparallel) configuration, as this arrangement is essential to the formation of the amyloid fibrils and the development of their Congophilic staining. The specific events triggering the formation of fibrils are unknown. The microenvironment, such as protein concentration, ionic strength, $\mathrm{pH}$, and the presence of specific enzymes, proteoglycans and other cellular components, may be critical. The influence of the aging process on this microenvironment and the consequent predisposition to fibril deposition is largely unknown. However, the clinical, pathological and biochemical characteristics of the age related amyloids are becoming better understood.

\section{Senile systemic amyloidosis}

Senile systemic amyloidosis (SSA) is the most common form of systemic amyloidosis, occurring in $25 \%$ of people over the age of 80 years. ${ }^{11}$ The major constituent of the amyloid fibrils in SSA is derived from normal TTR, previously known as prealbumin. ${ }^{1}$ The circulating tetrameric form of TTR has binding sites for thyroxin and retinal binding protein and thus has an important function in the transport of these substances.

TTR is also the major precursor for several heredofamilial forms of predominantly late onset amyloidosis (familial amyloidotic polyneuropathy (FAP), familial amyloidotic cardiomyopathy, and isolated vitreous amyloidosis). Studies of these autosomal dominant forms of amyloidosis have shown that specific point mutations in the TTR gene lead to single amino acid substitutions in TTR which are characteristic for each of the affected kindreds. To date, more than 40 point mutations have been found in association with familial TTR derived amyloidosis.

\section{CLINICAL FEATURES}

SSA is generally a very benign disorder. Although a small percentage of patients develop cardiomegaly with heart failure and/or arrhythmia, to our knowledge there have been no reported cases of clinical sequelae clearly resulting from SSA deposits in extracardiac tissues. In the small number of patients who develop massive cardiac infiltration by this type of amyloid, the clinical consequences seem to be relatively minor when compared with cardiac disease associated with primary (AL) amyloidosis. Twelve patients with massive cardiac amyloid infiltration associated with SSA have recently been evaluated. ${ }^{12}$ These patients were very old ( 82 to 92 years of age) and had a mean heart weight of $567 \mathrm{~g}$ (range $310-870 \mathrm{~g}$ ). All

Characteristics of age related amyloid

\section{Department of \\ Pathology,

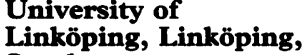 \\ Sweden \\ P Westermark \\ Correspondence to: Dr G G Cornwell III, Department of Pathology, Dartmouth-Hitchcock Medical Center, Lebanon, NH 03756, USA. \\ Accepted for publication 30 March 1995}

\begin{tabular}{llll}
\hline Type & $\% \geq$ years & Fibril protein & Reference \\
\hline Senile systemic & $25 \% \geq 80$ & Transthyretin & 1 \\
Aortic (media) & $100 \% \geq 90$ & Unknown (6 KD) & 2 \\
Seminal vesicles & $21 \% \geq 76$ & Unknown (14 KD) & 3 \\
Cerebral & $46 \% \geq 85$ & B protein & 4 \\
Islets of Langerhans & $50 \% \geq 60$ & Islet amyloid polypeptide & 5 \\
Atrium & $78 \% \geq 80$ & Atrial natriuretic factor & 6 \\
Adrenal & $68 \% \geq 70$ & Unknown & 7 \\
Choroid plexus & $100 \% \geq 60$ & Unknown & 8 \\
Articular & $77 \% \geq 60$ & Unknown & 9 \\
Pituitary & $\mathbf{8 0 \%} \geq 90$ & Unknown & 10 \\
\hline
\end{tabular}


amyloid deposits contained TTR. Amyloidosis was not suspected in any patient prior to death. Eight of the patients had a history (two months to two years) of uncomplicated congestive heart failure, all of whom responded at home to standard therapeutic measures. Arrhythmia occurred in all 12 patients (atrial fibrillation in nine, left bundle branch block in three, right bundle branch block in two, and left anterior hemiblock in one). However, no atrioventricular dissociation was seen, and conduction disturbance was not considered to be the cause of death in any patient. By distinction, cardiac failure and arrhythmia are leading causes of death in $\mathrm{AL}$ amyloidosis and are frequent occurrences in FAP.

\section{PATHOLOGY}

The amyloid deposits present in most organs or tissues are found mainly in vessel walls, but amyloid deposition in the heart is observed in vessels and as a diffuse or multifocal infiltration between muscle cells in the ventricles and atria. Adjacent affected muscle cells are often atrophied. The specialised conduction tissue is usually spared in $S S A,{ }^{12}$ in contrast to $\mathrm{AL}$ amyloidosis and FAP where extensive deposits of amyloid often affect the conduction system. In addition to the predominant involvement of the heart, SSA is usually observed in pulmonary vessels and alveolar walls.

The generalised nature of SSA has been examined in 27 tissues from 13 elderly patients (74 to 102 years of age) with large hearts associated with SSA. On immunohistochemistry, SSA deposits could be located in all tissues (to a varying degree) except brain. ${ }^{13}$ In the kidney these deposits were present only in the medulla.

\section{BIOCHEMISTRY}

TTR is encoded by a single copy gene on chromosome 18 and is synthesised mainly in the liver as a $147(55 \mathrm{kD})$ amino acid proprotein chain. After the signal sequence has been cleaved off, the monomeric 127 amino acid TTR forms dimers and tetramers. The tetrameric form of TTR present in serum is capable of binding two molecules of thyroxine and has independent binding sites for retinal binding protein. Each monomer contains two segments of $\beta$-pleated sheet, a structure common to all of the amyloid fibril proteins characterised to date. Whereas TTR associated with FAP has invariably been found to contain a mutation, the study of several hearts from very old patients ( $>80$ years) with SSA have shown normal monomeric TTR. ${ }^{14}$ Furthermore, studies of TTR cDNA $^{15}$ and genomic DNA ${ }^{14}$ have shown normal sequences. Thus, it is clear that a TTR mutation is not required for the deposition of senile systemic amyloid. A TTR mutation at position 122 has been identified in black patients initially reported to have SSA. However, these patients are best classified as having familial amyloidotic cardiomyopathy, and the name SSA should be used only for TTR amyloid occurring in advanced age and without the occurrence of a TTR mutation.
The amyloid fibrils of SSA contain intact TTR together with a family of TTR fragments, the longest of which appears to consist of the -COOH terminal amino acids 46-127. As fragments of consistent length have been found in a number of SSA hearts, it is speculated that these fragments may play a role in the pathogenesis of SSA. Similar fragments are present in amyloid associated with FAP, and in both FAP and SSA, TTR fragments may predominate over the presence of full length TTR molecules. It is not known whether proteolytic cleavage of TTR is a primary and significant event in the fibrillogenesis of TTR in either SSA or FAP.

\section{Senile aortic amyloid}

Aortic amyloid appears to be the most common form of localised amyloid, occurring in nearly all people over 50 years of age. There is growing evidence that there are three distinct forms, involving the media, intima and adventitia. The most common form occurs in the media, where it has been found in $97 \%$ of people over 50 years of age. It is much less common in the intima (35\% of people over 50 years old). Adventitial amyloid ( $<5 \%$ in the same population) is a manifestation of systemic amyloidosis.

\section{CLINICAL AND PATHOLOGICAL FEATURES}

The clinical significance of aortic amyloid is unclear, as there have not been any studies which have shown a causal relation between aortic amyloid and hypertension or dissecting aneurysm.

Medial amyloid is most often located in the inner half of the media and appears as nodules and thin streaks, frequently in proximity to elastin fibres. A number of studies have shown that the thoracic aorta is more commonly involved than the abdominal aorta. ${ }^{2}$ Intimal amyloid, unlike medial amyloid, is consistently associated with atheromatous lesions and appears as irregular lumps. Adventitial amyloid has been found in the connective tissue and in the walls of the vasa vasorum.

\section{BIOCHEMISTRY}

Although the adventitial form of aortic amyloidosis is a manifestation of SSA (that is, the amyloid fibrils are derived from $T T R^{13}$ ) or other forms of systemic amyloidosis, the chemical identity of the amyloid fibril proteins associated with medial and intimal forms is unknown. Both contain tryptophan and are permanganate resistant. However, recent studies indicate that these two forms of aortic amyloid represent two separate and distinct forms of amyloid. ${ }^{2}$ Isolated medial amyloid has been fractionated in $6 \mathrm{M}$ guanidine and found to contain a dominant protein of less than $6 \mathrm{kD}$ in molecular weight. An antiserum raised against this protein reacts specifically with medial amyloid but not with intimal amyloid. Moreover, this antibody fails to react with a wide range of known amyloid types of either systemic or local distribution. $^{2}$ 
OTHER FORMS OF VASCULAR AMYLOID

Senile amyloid angiopathy has been described in a variety of other vessels, but the biochemical similarities between deposits in different vascular locations remains unknown. Studies by Mucchiano et $\mathrm{al}^{2}$ have demonstrated that medial amyloid of the common carotid and temporal arteries reacts with antiserum raised against aortic medial amyloid. These findings raise the possibility that this form of senile aortic amyloid represents a systemic vascular amyloid, possibly derived from locally produced precursor proteins.

A form of senile vascular amyloidosis derived from the $\mathrm{N}$-terminus of apolipoprotein $\mathrm{Al}$ (apoA1) was recently reported to occur commonly in the lungs of dogs over 10 years of age. ${ }^{16}$ Although this form of amyloidosis has not yet been documented in humans, apoA1 should be considered as a potential amyloid precursor when unknown forms of senile vascular amyloidosis are evaluated.

\section{Seminal vesicle amyloid}

Seminal vesicle amyloid has been found in 5\% of patients under 60 years of age and in $21 \%$ of those above the age of 76 years. ${ }^{3}$

\section{CLINICAL AND PATHOLOGICAL FEATURES}

There are no known clinical consequences of seminal vesicle amyloid deposition. Amyloid deposits are located subepithelially in the lamina propria, usually as distinct lumps. They may be present in the vesicular lumina as well.

\section{BIOCHEMISTRY}

Seminal vesicle amyloid is the only localised amyloid which has been shown to be permanganate sensitive. Although the amyloid fibril protein has not been characterised, an antibody raised against a $14 \mathrm{kD}$ protein extracted from the fibrils labels the amyloid specifically. ${ }^{17}$ This antibody also labels a percentage of normal epithelial cells in vesicles without amyloid deposits. These findings suggest that the precursor of the amyloid fibrils is synthesised by epithelial cells, and that the precursor is secreted by epithelial cells of a certain age or functional state. The capacity of normal vesicular secretion to block the antibody reaction supports this finding. It seems, therefore, that seminal vesicular amyloid is the first member of the amyloid family to be derived from the secretory protein of an exocrine cell. ${ }^{17}$

\section{Amyloid associated with Alzheimer's disease}

CLINICAL AND PATHOLOGICAL FEATURES

Alzheimer's disease afflicts about $10 \%$ of people over the age of 65 years and as many as $47 \%$ over the age of 85 years. The disease is manifested by progressive dementia in association with neurodegeneration. The brain shows characteristic microscopic abnormalities: (a) neurotic plaques composed of argyrophilic neurotic processes surrounding a core of A amyloid; (b) neurofibrillary tangles consisting of intracellular paired helical filaments derived from abnormally phosphorylated microtubular tau ( $\tau$ ) protein; (c) meningocerebrovascular $A \beta$ amyloid; and (d) isolated neuronal degeneration and atrophy. One or more of these findings may be present in the absence of dementia and thus a definitive diagnosis of $\mathrm{Alz}$ heimer's disease requires both dementia and the pathological findings described above.

\section{BIOCHEMISTRY}

$\beta$ amyloid fibril protein is a $4.2 \mathrm{kD}$ peptide 39-43 amino acids long, called $\beta$ protein, A4 protein or $A \beta{ }^{418}$ This peptide is a proteolytic product of a much larger transmembrane amyloid precursor protein ( $\beta P P$ ) encoded by a gene located on the long arm of chromosome 21 . Alternative splicing of the primary transcript of 18 exons in the $\beta P P$ gene gives rise to distinctive messengers coding for $\beta P P$ s which are $695,714,751$, or 770 amino acids long. ${ }^{19}$ The proposed functions for $\beta P P$ include cellular adhesion, protease inhibition, regulation of cell growth, and surface receptor activity.

A $\beta$ structure resides between residues 597 and 637 at the -COOH terminus of the PP695 molecule, which is the dominant isoform in the brain. If cleavage of $\beta P P$ occurs within the $A \beta$ molecule, intact $A \beta$ cannot be formed and amyloid is not deposited. A second pathway splits the $\beta P P$ molecule closer to the $\mathrm{N}$-terminus, leading to production of intact $A \beta$ following additional cleavage at the C-terminal end of the $\beta P P$ molecule. ${ }^{20}$ It has recently been shown that $A \beta$ can be produced as a soluble peptide in vitro by metabolically normal cells. Thus, during normal aging, a balance between these two pathways may exist, a balance which may be disrupted in Alzheimer's disease. ${ }^{19}$ In addition, the varying length of the $A \beta$ molecules may be a factor in determining whether amyloid formation occurs. ${ }^{21}$ The pathological process in Alzheimer's disease occurs at an earlier age in patients with Down syndrome, possibly as a result of upregulation of $\beta P P$ and $\tau$ protein synthesis.

THE ROLE OF A $\beta$ AMYLOID IN THE PATHOGENESIS OF ALZHEIMER'S DISEASE The relation between $A \beta$ amyloid deposition and the dementia of Alzheimer's disease remains controversial (see reviews ${ }^{22}$ ). For example, there is often no strong correlation between the quantity of amyloid and the degree of dementia. $A \beta$ amyloid deposits are not pathognomonic of Alzheimer's disease, as they can occur in the brains of elderly subjects without a clinical history of dementia. The relation between the neurofibrillary tangles, neurotic plaques and cerebrovascular amyloid deposits is still not clear.

$\mathrm{A} \beta$ amyloid has been reported to have a direct toxic effect on neurons. For example, fibrils derived from synthetic $A \beta$ or $A \beta$ amyloid have been found to be toxic for neurons in 
vitro or when administered intracerebrally in experimental animals. ${ }^{24}$ It is also possible that the toxic effect of $A \beta$ amyloid is related to its concentration and density, a conclusion supported by some animal studies. ${ }^{24}$

\section{Amyloid of pancreatic islets}

Amyloid deposits localised strictly to the islets of Langerhans are very common in old people. Their frequency and distribution increase with age, and small deposits have been seen in more than $50 \%$ of people over 60 years of age. However, the frequency and degree of amyloid infiltration is much higher in patients with type 2 diabetes mellitus. Up to $95 \%$ of such patients contain some islet amyloid, and about two thirds of the patients have deposits in at least $25 \%$ of their islets. ${ }^{25}$

\section{PATHOLOGICAL FEATURES}

The amyloid is strictly limited to the islets and is found between the epithelial cells and the vessels. Sometimes the amyloid deposits outline the exterior of the islets. Progressive deposition of the amyloid in the pancreatic islets reduces the beta cell mass, but this reduction is not sufficient per se to account for the diabetic state in these patients. On electron microscopy, even very small deposits are extracellular and bundles of amyloid fibrils are typically oriented within invaginations extending into beta cells. The importance of amyloid is difficult to assess, but it is possible that increasing deposits give rise to the failure of oral anti-diabetic therapy seen late in type 2 diabetes.

Interestingly, recent studies have shown that islet amyloid fibrils may be cytotoxic to beta cells. This in vitro cytotoxicity requires direct contact of the fibrils with the cell surfaces of the affected beta cells. This mechanism may possibly contribute to the loss of beta cell mass observed in patients with type 2 diabetes, but further studies are needed.

\section{BIOCHEMISTRY}

The nature of islet amyloid has long been a puzzle, with insulin often suspected as the major amyloid fibril protein. However, it was discovered recently that islet amyloid represents an aggregated form of a previously unknown islet derived hormone identified as islet amyloid polypeptide (IAPP) ${ }^{52627}$ or amylin. ${ }^{28}$ IAPP is encoded by a gene on chromosome 12. It is expressed as an 89 amino acid prepropeptide $^{2930}$ which is subsequently cleaved to form the 37 amino acid IAPP molecule. IAPP is synthesised and secreted predominantly by islet beta cells, co-localised with insulin in the beta cell secretory vesicles, and is co-secreted in a biphasic pattern with insulin in response to glucose and other secretagogues. The amount of IAPP secreted on a molar basis is about $1-10 \%$ that of insulin, and basal plasma concentrations of IAPP in humans are in the $2-15 \mathrm{pM}$ range.

IAPP is nearly $50 \%$ identical with the neuro- peptide calcitonin gene related peptide (CGRP) but, in contrast to CGRP, IAPP has a short and unique central segment which is fibrillogenic. ${ }^{29}$ The fibrillogenic potential of IAPP in humans, cats, and non-human primates seems to be related to the amino acid sequence present in positions $24-28 .^{31}$ Specifically, the Gly-Ala-Ile-Leu-Ser residues in positions $24-28$ seems to be critically related to fibrillogenesis in humans and cats. In vitro experiments have shown that synthetic peptides corresponding to both full length IAPP and human IAPP segment $20-29$ have a strong tendency to form amyloid-like fibrils in vitro. ${ }^{31}$

In addition to the importance of this inherently amyloidogeneic segment, other factors are likely to be of importance in the development of islet amyloidosis and type 2 diabetes. For example, overproduction of IAPP (resulting in increased local concentrations) or aberrations in synthesis, molecular processing or release of IAPP ${ }^{32}$ are additional potentially important factors in the development of this syndrome.

\section{PHYSIOLOGY OF IAPP}

The normal function of IAPP is not known, but several potentially important biological effects have been proposed and/or documented. These include regulation of glucose metabolism, potent hypocalcaemic effects, anorectic effects, and vasodilatation. ${ }^{2633}$ The suggested roles for IAPP in glucose regulation include reduced insulin secretion by beta cells and increased peripheral insulin resistance of muscle cells. In general, however, the IAPP concentrations used experimentally have been much higher than those measured physiologically, and thus the role of IAPP in the pathogenesis of type 2 diabetes mellitus remains unclear.

\section{Isolated atrial amyloid}

Isolated atrial amyloid (IAA) has hitherto been found only in the atria, although theoretically it may occur at any site expressing atrial natriuretic factor (ANF). IAA is one of the most prevalent types of senile amyloidosis and has been found in about $80 \%$ of non-selected necropsy cases over 80 years of age. ${ }^{1134}$ The atrial amyloid deposits are usually small and tend to coat muscle cells. On electron microscopy, a close relation between the amyloid fibrils and cell membranes of muscle cells is seen, and apparent intracellular amyloid fibrils have been identified. ${ }^{3536}$

\section{CLINICAL FEATURES}

The pathogenesis and significance of IAA are incompletely understood, but IAA may result from unknown aberrations involving the storage or release of ANF. This condition is more prevalent in patients with chronic cardiac insufficiency, a condition associated with increased plasma concentrations of ANF, and in other cardiac diseases. ${ }^{37}$ No definite clinical consequence has been identified in IAA. 


\section{BIOCHEMISTRY}

The cardiac atria are endocrine organs, expressing the polypeptide hormone ANF. ANF is expressed as a 151 amino acid prepropolypeptide and is stored in intracytoplasmic granules as a 126 amino acid prohormone. At release, proteolytic cleavage occurs, giving rise to the mature 28 amino acid ANF, which is the C-terminal part of the prohormone. Purification studies have shown that the major fibril peptide from IAA is in fact ANF. ${ }^{638}$ Thus, abnormal cleavage does not seem to be involved in the process of amyloidogenesis. Immunohistochemical studies have shown that, in addition to intact ANF, the IAA fibrils may contain proANF and brain natriuretic peptide. ${ }^{36}$

\section{Other hormone derived amyloid forms}

Other endocrine organs which frequently have age related amyloid deposits are the pituitary and parathyroid glands. In a postmortem study, amyloid deposits were found in more than $80 \%$ of pituitary glands from subjects over 90 years of age. ${ }^{10}$ Similar frequencies have been observed in the parathyroid gland. Irrespective of the patients' ages, endocrine tumours also contain amyloid, especially medullary carcinoma of the thyroid and islet cell tumours. Parathyroid and pituitary adenomas may contain amyloid as well. Therefore, the mechanisms of amyloidogenesis in aged endocrine tissues and in endocrine tumours are probably similar. Interestingly, senile amyloid deposits have not been described in the thyroid.

It has long been suspected that the amyloid deposits in endocrine tumours and organs are related to hormone production. Direct proof was first obtained by the finding that calcitonin was associated with amyloid in medullary carcinoma of the thyroid. ${ }^{39}$ However, IAPP and ANF remain the only senile amyloid fibril proteins known to be derived from polypeptide hormones.

\section{Intracellular age related amyloid}

Amyloid deposits are most commonly present in extracellular locations. However, fibrils with the properties of amyloid are sometimes observed intracellularly. The most well known example is the occurrence of neurofibrillary tangles in neurons. Similar, although possibly unrelated, intracellular amyloid fibril aggregates occur commonly in choroid plexus epithelial cells ${ }^{8}$ and adrenal cortical cells. ${ }^{7}$

Only the choroid plexus amyloid (CPA) has been studied in detail. CPA is very prevalent and, in one study, was found in all subjects over 60 but not below 35 years of age. ${ }^{8}$ Its constant occurrence in aging people has made CPA useful in forensic medicine as a rapid rough method for determining the age of severely injured bodies. The protein nature of CPA is unknown but may be related to the cytoskeleton. ${ }^{40}$
Other types of localised amyloid

Many other types of age related localised amyloid have been observed, some of which have unique immunological features. Amyloid associated with sclerocalcific heart valves appears to differ from any other cardiovascular amyloid characterised to date. ${ }^{41}$ Similarly, amyloid associated with porcine bioprosthetic valves does not show immunological cross reactivity with other known amyloid proteins. Small asymptomatic deposits of amyloid are commonly found in articular and periarticular tissues. These deposits are generally localised to cartilage, synovial membrane and fibrous capsule. ${ }^{9}$ There is evidence that amyloid associated with the hip capsule is frequently of the SSA type. However, age related amyloid associated with other joint structures (knee capsule, hip cartilage and sternoclavicular cartilage) seems to contain a distinctive type of amyloid. ${ }^{9}$

\section{Conclusion}

The age related amyloids represent an extremely varied group of pathological entities. Some forms of amyloid, such as aortic and choroid plexus, are present in virtually all elderly people. On the basis of currently available information, all major forms of senile amyloidosis seem to be derived from normally synthesised proteins. TTR seems to have the most distinctive characteristics of all the amyloid fibril proteins of producing a generally benign amyloidosis in its native form (SSA) and a malignant, lethal amyloidosis in its mutant form (FAP).

Many of the localised age related amyloids do not appear to cause clinical disease. However, although the complex mechanisms are not completely understood, the $\beta$ protein and IAPP derived amyloids are generally considered to have significant links to their respective associated clinical diseases (Alzheimer's disease and type 2 diabetes mellitus). Although the precursor protein of the intimal type of senile aortic amyloid is unknown, its relation to atherosclerosis deserves further study. Irrespective of how the debate regarding the pathological significance of the age related amyloids evolves, further characterisation of their fibril protein structures promises to advance our understanding of the entire complex and puzzling family of amyloidoses.

Our research referred to in this review was supported in part by Cancer Center Support Grants CA 23108, Grant R01 DK 36734 of the National Institute of Diabetes and Digestive and Kidney Disease, the W. P. Cornwell Amyloid Research Fund, the Swedish Medical Research Council (Project \#5941), the Swedish Diabetes Association, the Association Again
milial Amyloidosis (FAMY), and the Amyl Foundation.

1 Sletten K, Westermark P. Senile cardiac amyloid is related to prealbumin. Scand f Immunol 1980;12:503-6.

. Westermark $P$. Senile Mucchiano G, Cornwell GG III, Westermark P. Senile aortic amyloid: evidence for two distinct

3 Pitkänen P, Westermark P, Cornwell GG III, Murdoch W. Amyloid of the seminal vesicles: a distinctive and common 110:64-9.

4 Glenner GG, Wong CW. Alzheimer's disease: initial report of the purification and characterization of a novel cerebrovascular amyloid protein. Biochem Biophys Res Commun 1984;120:885-90.

5 Westermark P, Wernstedt C, Wilander E, Sletten K. A nove peptide in the calcitonin gene related peptide family as an 
amyloid fibril protein in the endocrine pancreas. Biochem Biophys Res Commun 1986;140:827-31.

6 Johansson B, Wernstedt C, Westermark P. Atrial natriuretic peptide deposited as atrial amyloid fibrils. Biochem Biophys Res Commun 1987;148:1087-92.

7 Eriksson L, Westermark P. Age related accumulation of amyloid inclusions in adrenal cortical cells. Am $\mathcal{f}$ Pathol 1990;136:461-6.

8 Eriksson L, Westermark P. Intracellular neurofibrillary tangle-like aggregations. A constantly present amyloid alteration in the aging choroid plexus. Am $\mathcal{F}$ Pathol 1986; 125:124-9.

9 Goffin YA, McCrickard EL, Ameryckx JP, Malmendier CL, Hiden M, Cornwell GG III. Amyloidosis of the joints: Evidence that human hip capsules have a unique predisposition for amyloid of the senile systemic type. Appl Pathol 1985;3:88-95.

10 Tashima T, Kitamoto T, Tateishi J, Ogomori K, Nakagaki H. The incidence and characterization of age related amyloid deposits in the human anterior pituitary gland. Virchows deposits in the human anterior pituitary gland.

11 Cornwell GG III, Murdoch WL, Kyle RA, Westermark P, Pitkänen $P$. The frequency and distribution of senile cardiovascular amyloid: A clinico-pathologic correlation. Am $\mathcal{F}$ Med 1983;75:618-25.

12 Johansson B, Westermark P. Senile systemic amyloidosis: a clinico-pathological study of twelve patients with massive amyloid infiltration. Int $\mathcal{F}$ Cardiol 1991;32:83-92.

13 Pitkänen P, Westermark P, Cornwell GG III. Senile systemic amyloidosis. Am $\mathcal{F}$ Pathol 1984;117:391-9.

14 Westermark P, Sletten K, Johansson B, Cornwell GG III. Fibril in senile systemic amyloidosis is derived from normal Fibril in senile systemic amyloidosis is derived from norma

15 Christmanson L Betsholtz C, Gustavsson A, Johansson B, Christmanson L, Betsholtz C, Gustavsson A, Johansson B,
Sletten K, Westermark P. The transthyretin cDNA sequence is normal in transthyretin-derived senile systemic amyloidosis. FEBS Lett 1991;281:177-80.

16 Johnson KH, Sletten K, Hayden DW, O Brien TD, Roertgen $\mathrm{KE}$, Westermark P. Pulmonary vascular amyloidosis in aged dogs. A new form of spontaneously occurring amyloidosis derived from apolipoprotein A1. Am $₹$ Pathol 1992;141: 1013-19

17 Cornwell GG III, Westermark GT, Pitkanen P, Westermark P. Seminal vesicle amyloid: the first example of exocrine cell origin of an amyloid fibril precursor. $\mathcal{F}$ Pathol 1992; 167:297-303.

18 Masters CL, Simms G, Weinman NA, Multhaup G, Masters CL, Simms G, Weinman NA, Multhaup G, McDonald BL, Beyreuther K. Amyloid plaque core protein in Alzheimer's disease and

19 Mullan M, Crawford F. Genetic and molecular advances in Alzheimer's disease. Trends Neurosci 1993;16:398-403.

20 Golde TE, Estus S, Younkin LH, Selkoe DJ, Younkin SG. Processing of the amyloid protein precursor to potentially amyloidogenic derivatives. Science 1992;255:728-30.

21 Selkoe DJ. Physiological production of the $\beta$-amyloid and the mechanism of Alzheimer's disease. Trends Neurosci 1993;16: 403-9.

22 Yankner BA, Mesulam MM. $\beta$-amyloid and the pathogenesis of Alzheimer's disease. $N$ Engl $\mathcal{Y}$ Med 1991;325:1849-57.

23 Selkoe DJ. Alzheimer's disease: a central role for amyloid. $\Im$ Neuropathol Exp Neurol 1994;53:438-47.

24 Kowall NW, Beal MF, Busciglio J, Duffy LK, Yankner BA. An in vivo model for the neurodegenerative effects of $\beta$ amyloid and protection by substance P. Proc Natl Acad Sci USA 1991;88:7247-51.
25 Westermark P. Amyloid and polypeptide hormones: what is their inter-relationship? Amyloid 1994;1:47-60.

26 Westermark P, Johnson KH, O'Brien TD, Betsholtz C. Islet amyloid polypeptide - a novel controversy in diabetes research. Diabetologia 1992;35:297-303.

27 Westermark P, Wernstedt C, Wilander E, Hayden DW, O'Brien TD, Johnson KH. Amyloid fibrils in human insulinoma and islets of Langerhans of the diabetic cat are derived from a neuropeptide-like protein also present in normal islet cells. Proc Natl Acad Sci USA 1987;84: 3881-5.

28 Cooper GJS, Willis AC, Clark A, Turner RC, Sim RB, Reid KBM. Purification and characterization of a peptide from amyloid-rich pancreases of type 2 diabetic patients. Proc Natl Acad Sci USA 1987;84:8628-32.

29 Betsholtz C, Svensson V, Rorsman F, Engstrom U, Westermark GT, Wilander E, et al. Islet amyloid polypeptide termark GT, Wilander E, et al. Islet amyloid polypeptide (LAPP): cDNA cloning and identification of an amy-
loidogenic region associated with the species-specific ocloidogenic region associated with the species-specific oc-
currence of age-related diabetes mellitus. Exp Cell Res 1989; currence of a

30 Sanke T, Bell GI, Sample C, Rubenstein AH, Steiner DF. An islet amyloid peptide is derived from an 89-amino acid precursor by proteolytic processing. $千$ Biol Chem 1988;263: 17243-6.

31 Westermark P, Engström U, Johnson KH, Westermark GT, Betsholtz C. Islet amyloid polypeptide: pinpointing amino acid residues linked to amyloid fibril formation. Proc Natl Acad Sci USA 1990;87:5036-40.

32 Westermark GT, Christmanson G, Terenghi G, Permert J, Betsholtz C, Larsson J, et al. Islet amyloid polypeptide: demonstration of mRNA in human pancreatic islets by in situ hybridization in islets with and without amyloid deposits. Diabetologia 1993;36:323-8.

33 Johnson KH, O'Brien TD, Betsholtz C, Westermark P. Islet amyloid polypeptide: mechanisms of amyloidogenesis in the pancreatic islets and potential roles in diabetes mellitus. Lab Invest 1992;66:522-35.

34 Westermark P, Johansson B, Natvig JB. Senile cardiac amyloid: Evidence of two different amyloid substances in the aging heart. Scand F Immunol 1979;10:303-8.

35 Johansson $B$, Westermark $P$. The relation of atrial natriuretic factor to isolated atrial amyloid. Exp Mol Pathol 1990;52: 266-78.

36 Pucci A, Wharton J, Arbustini E, Grasso M, Diegoli M, Needleman $\mathrm{P}$, et al. Atrial amyloid deposits in the failing human heart display both atrial and brain natriuretic peptide-like immunoreactivity. $\mathcal{F}$ Pathol 1991;165:235-41.

37 Looi L-M. Isolated atrial amyloidosis: a clinicopathologic study indicating increased prevalence in chronic heart disstudy indicating increased prevale

38 Linke RP, Voigt C, Störkel FS, Eulitz M. N-terminal amino acid sequence analysis indicates that isolated atrial amyloid is derived from atrial natriuretic peptide. Virchows Arch $B$ Cell Pathol 1988;55:125-7.

39 Sletten K, Westermark P, Natvig JB. Characterization of amyloid fibril proteins from medullary carcinoma of the thyroid. $₹$ Exp Med 1976;143:993-8.

40 Eriksson L, Westermark P. Characterization of intracellular amyloid fibrils in the human choroid plexus epithelial cells. Acta Neuropathol 1990;80:597-603.

41 Goffin YA, Murdoch W, Cornwell GG III, Sorenson GD. Microdeposits of amyloid in sclerocalcific heart valves: a histochemical and immunofluorescence study. $\mathcal{f}$ Clin Pathol 1984;36:1342-9. 